\title{
The direct antiglobulin (Coombs) test in megaloblastic anaemia
}

\author{
J. FORSHAW AND LILIAN HARWOOD
}

\author{
From the Sefton General Hospital, Liverpool
}

SYNOPSIS Folic acid deficiency with the picture of a megaloblastic bone marrow may develop in haemolytic anaemia, and, on the other hand, both vitamin $B_{12}$ and folic acid deficiency may produce signs of haemolysis. As the correct interpretation of a positive antiglobulin reaction associated with megaloblastic erythropoiesis is particularly important, the effect of deficiency of vitamin $B_{12}$ and folic acid on the results of the test was investigated in 32 patients with vitamin $B_{12}$ or folic acid deficiency and a positive antiglobulin reaction was obtained in ten. There was no correlation between the result of the test and the degree of anaemia, and there was no significant difference between the incidence of positive results associated with deficiency of vitamin $B_{12}$ or folic acid. In determining the significance of a positive result, the time interval before agglutination occurs is sometimes of greater value than the strength of the reaction or the result of the gamma globulin neutralization test.

In both the acquired and hereditary types of haemolytic anaemia, the demands of increased red cell production may result in folic acid deficiency and a megaloblastic bone marrow (Chanarin, Dacie, and Mollin, 1959). It is important, therefore, to look for evidence of associated haemolytic disease in patients with megaloblastic erythropoiesis. As deficiency of both vitamin $B_{12}$ and folic acid reduces the erythrocyte life span, resulting in a low haptoglobin level (Owen, Carew, Cowling, Hoban, and Smith, 1960) and sometimes an increase in unconjugated bilirubin in the serum, the diagnosis of a primary haemolytic disorder may be difficult to determine initially.

The result of the direct antiglobulin test is of particular importance in the diagnosis of acquired auto-immune haemolytic anaemia. However, a positive result is not absolutely specific (Dacie and Lewis, 1963), and there has been one detailed report of a patient in whom a positive antiglobulin test was produced by pernicious anaemia (Selwyn and Alexander, 1951). In order to clarify the interpretation of a positive reaction in patients with megaloblastic erythropoiesis, we have investigated the effect of vitamin $B_{12}$ and folic acid deficiency on the results of the test.

\section{MATERIAL AND METHODS}

Thirty-two patients with megaloblastic anaemia were Received for publication 28 March 1964. studied. The cause of the anaemia was determined by the appropriate use of serum vitamin $B_{12}$ assay (Matthews, 1962), the measurement of the absorption of vitamin $B_{12}$ (Schilling, 1953), and folic acid (Anderson, Belcher, Chanarin, and Mollin, 1960), and the estimation of formiminoglutamic acid excretion in the urine (Kohn, Mollin, and Rosenbach, 1961).

The direct and indirect antiglobulin tests and the gamma globulin neutralization test were carried out as described by Dacie and Lewis (1963). The blood samples were kept at room temperature and the tests were carried out within two hours of collection. In the two patients with agglutination up to a titre of $1: 256$, the tests were repeated using blood collected directly into saline warmed to $37^{\circ} \mathrm{C}$. The result was regarded as positive when agglutination occurred within five minutes. When a positive result was obtained, the direct antiglobulin test was repeated at intervals while the patient was receiving treatment with either vitamin $B_{12}$ or folic acid.

\section{RESULTS}

The results are summarized in Table I. The direct antiglobulin test was positive in 10 patients, and on each occasion agglutination occurred after an interval of between four and five minutes. There was no correlation between the results of the tests and the degree of anaemia, and there was no significant difference between the results in the patients with vitamin $B_{12}$ deficiency and in those with folic acid deficiency. In six of the positive reactions the highest titre was $1: 16$ or less and agglutination was not 
TABLE I

RESULTS OF THE DIRECT ANTIGLOBULIN TEST

No. of Patients Titres

Tested Positive Undiluted 1:4 1:16 1:64 1:256

\begin{tabular}{lrllllll}
\hline $\begin{array}{l}\text { Pernicious anaemia } \\
\text { Gastrectomy }\end{array}$ & 2 & 5 & - & -3 & 1 & 1 \\
$\begin{array}{l}\text { Resection of } \\
\text { Nuleum }\end{array}$ & 1 & 0 & - & -1 & - & - & - \\
$\quad$ deficienal & 9 & 3 & 1 & -1 & - & 1 \\
Steatorrhoea & 2 & 0 & - & - & - & - & - \\
Puerperium & 2 & 1 & - & - & - & 1 & - \\
Myelofibrosis & 2 & 0 & - & - & - & - & -
\end{tabular}

heavy, but in four agglutination was heavy, and in two the result was positive up to a titre of $1: 256$. In three out of five cases agglutination of the red cells was inhibited by the addition of gamma globulin to the antiglobulin serum (Table II), but these results were not related to the height of the titre of the antiglobulin test. In the two patients in whom the antiglobulin test was positive at a titre of $1: 256$, the serum was tested for complete and incomplete antibodies active at room temperature and at $37^{\circ} \mathrm{C}$., with negative results.

\section{TABLE II}

RESULTS OF THE GAMMA GLOBULIN NEUTRALIZATION TEST

\begin{tabular}{lcl} 
& $\begin{array}{l}\text { Titre of } \\
\text { Antiglobulin Test }\end{array}$ & Type of Reaction \\
\hline Pernicious anaemia & $1: 16$ & Non-gamma \\
Pernicious anaemia & $1: 16$ & Gamma \\
Pernicious anaemia & $1: 256$ & Gamma \\
Nutritional anaemia & $1: 256$ & Non-gamma \\
Gastrectomy & $1: 4$ & Gamma
\end{tabular}

The antiglobulin test became negative in nine patients after they had received treatment with vitamin $\mathbf{B}_{12}$ or folic acid for between one and three weeks. In one patient with pernicious anaemia and a positive reaction up to a titre of $1: 16$, the result had not altered after receiving vitamin $B_{12}$ for 10 weeks.

\section{DISCUSSION}

The antiglobulin test detects protein adsorbed to cells, but a positive reaction does not necessarily mean that the patient is suffering from auto-immune haemolytic anaemia. If the antiglobulin test is performed on cells obtained from clotted or defibrinated blood, which has been stored in the refrigerator at $4^{\circ} \mathrm{C}$., then the reaction may be positive due to adsorption of incomplete cold antibodies normally present in the serum (Dacie, 1950). In the positive direct antiglobulin reactions described here, either clotted blood was kept at room temperature for less than two hours before th test was performed or the blood was collected directly into saline warmed to $37^{\circ} \mathrm{C}$. Sensitization cold antibodies is unlikely, therefore, to have caused these positive reactions.

Positive reactions, which are not due to cola antibodies, have been reported in a variety of chronce diseases (Dunsford and Grant, 1959; Dacie ang Lewis, 1963), but apart from one patient with pernicious anaemia (Selwyn and Alexander, 1951 megaloblastic anaemias are not included in these lists of disorders. These 'non-specific' reactions we usually weak and not affected by the addition of gamma globulin to the antiglobulin serum. In four of the 10 positive reactions described here, however, there was heavy agglutination with antiglobulin concentrations of less than $1: 16$, and in three out of five cases the protein coating the cells was of the gamma globulin type. A moderately strong reaction. which is inhibited by the addition of gamma globulin, may therefore be non-specific. The time of the onset of agglutination appears to be a valuable indication of the specificity of the reaction; in the cases of vitamin $B_{12}$ and folic acid deficiencos agglutination never occurred in less than fou minutes, whereas, in our experience, agglutination occurs more rapidly in cases of auto-immun haemolytic anaemia.

\section{REFERENCES}

Anderson, B., Belcher, E. H., Chanarin, I., and Mollin, D. L. (19609 Brit. J. Haemat., 6, 439.

Chanarin, I., Dacie, J. V., and Mollin, D. L. (1959). Ibid., 5, 245. Dacie, J. V. (1950). Nature (Lond.), 166, 36.

- and Lewis, S. M. (1963). Practical Haematology, 3rd ed., p 166-176. Churchill, London.

Dunsford, I., and Grant, J. (1959). The Antiglobulin (Coombs) Test Laboratory Practice, p. 114. Oliver \& Boyd, Edinburgh.

Kohn, J., Mollin, D. L., and Rosenbach, L. M. (1961). J. clin. Pathog 14,345 .

Matthews, D. M. (1962). Clin. Sci., 22, 101.

Owen, J. A., Carew, J. P., Cowling, D. C., Hoban, J. P., and Smith, (1960). Brit. J. Haemat., 6, 242.

Schilling, R. F. (1953). J. Lab. clin. Med., 42, 860.

Selwyn, J. G., and Alexander, S. S. (1951). Brit. med. J., 1, 564.

\section{ADDENDUM}

Since this paper was completed, a further 27 case of megaloblastic anaemia due to deficiency of vitamin $B_{12}$ or folic acid have been studied, and the direct antiglobulin test was positive in 11 . Two reactions were positive to a titre of $1: 256$, four to $1: 64$ four to $1: 16$, and one to $1: 4$. In the two positive reactions at a titre of $1: 256$, agglutination occurred in three minutes and one minute respectively, but otherwise agglutination occurred between four an $\Phi$ five minutes. The reaction was of the non-gammotion globulin type in seven cases tested. 